\title{
Comunicação
}

[Communication]

\section{Soroepidemiologia da brucelose canina causada por Brucella canis e Brucella abortus na cidade de Alfenas, MG}

[Seroepidemiology of canine brucellosis caused by Brucella canis and Brucella abortus in Alfenas, MG, Brazil]

\author{
A.C. Almeida ${ }^{1}$, A. Santorelli ${ }^{2}$, R.M.Z. Bruzadelli ${ }^{3}$, M.M.N.F. Oliveira ${ }^{1}$ \\ ${ }^{1}$ Faculdades Federais Integradas de Diamantina \\ Rua da Glória, 187, Centro \\ 39100-000 - Diamantina, MG \\ ${ }^{2}$ Bolsista de iniciação científica/PIBIC/CNPq - UNIFENAS \\ ${ }^{3}$ Faculdade de Medicina Veterinária - UNIFENAS
}

A brucelose canina tem como etiologia Brucella canis. Na maioria dos casos, porém, a doença tem também como causa a infecção por Brucella abortus. A infecção é de caráter crônico em cães, canídeos silvestres e no homem, tendo distribuição mundial.

Com o objetivo de avaliar a prevalência da brucelose canina causada por $B$. canis $e B$. abortus na cidade de Alfenas, MG, foram analisadas amostras de soro sangüíneo de 635 cães, coletadas durante a campanha de vacinação anti-rábica, em setembro de 2001. Em 27 postos de vacinação, foi coletado o sangue de um em cada 10 cães e os dados referentes à faixa etária, sexo, sinais clínicos e procedência dos cães foram anotados.

O diagnóstico de $B$. canis foi realizado pelo teste de imunodifusão em gel de agarose, com kit produzido pelo Instituto de Tecnologia do Paraná (TECPAR), contendo antígenos solúveis de $B$. ovis, seguindo as recomendações do fabricante.

Para o diagnóstico de B. abortus, utilizaram-se antígenos convencionais (amostra 119-3, TECPAR) existentes no Brasil, usando o teste do antígeno acidificado tamponado para triagem. Os soros reagentes foram submetidos à soroaglutinação lenta com 2- mercaptoetanol (2-
ME SAL), como teste confirmativo. As duas técnicas foram conduzidas como recomendado por Alton et al. (1988) e foram considerados positivos os soros com título maior ou igual a 1:200 (Charmichael, Shin, 1996).

A prevalência de $B$. canis foi de 14,2\% (90/635) e a de $B$. abortus de $18,1 \%$ (115/635); no teste de triagem apenas $2,8 \% \quad(18 / 635)$ foram confirmados.

Os dados obtidos para B. canis são compatíveis com os da literatura brasileira e internacional, que mostram índices de prevalência entre 0,84 (Moraes et al., 2002) e 57,1\% (Medgi et al., 1999), sendo variáveis com a população estudada e com a técnica de diagnóstico empregada.

Para B. abortus a literatura também apresenta índices de prevalência baixos. Molnar et al. (2001), utilizando soroaglutinação lenta, observaram prevalência de $2,5 \%$. A prevalência de $2,8 \%$ pode estar ligada aos riscos de contaminação de cães dada a expressiva atividade de pecuária leiteira existente na região, com índice de prevalência para a brucelose bovina de 4,6\% (Augusto et al., 2002).

Em relação às características dos positivos, $56,6 \%$ eram sem raça definida e não foi

Colaboradores: A.G. Teixeira, A.V. Siqueira, F.B. Faria, A.C. Lobo, E.F.A. Ribeiro T.M.P. Soares, V.M.O. Bernis, P.A.S. Ferreira Recebido para publicação em 24 de outubro de 2002 
observada diferença significativa entre sexo, sendo $50 \%$ de machos e $48,6 \%$ de fêmeas; os proprietários não declararam o sexo de $1,4 \%$.

Maior freqüência de positivos ocorreu em animais acima de um ano de idade, com $28,7 \%$ entre um e dois anos e 49,1\% acima de dois anos. De acordo com a literatura, a maior freqüência de cães reagentes é com a idade acima de um ano ou em idade reprodutiva (Maia et al., 1999; Medgi et al., 1999; Almeida et al., 2001; Marassi et al., 2003).

Os sinais clínicos declarados foram: aborto $(5,5 \%)$, orquite $(1,8 \%)$, natimorto $(3,7 \%)$ e dermatite $(2,7 \%)$. Em $86,1 \%$ dos casos os proprietários não observaram sinais clínicos. Medgi et al. (1999) e Almeida et al. (2001) mencionaram animais sorologicamente positivos com os mesmos sinais clínicos, mas a maioria costuma ser de cães assintomáticos (Moraes et al., 2002).
A maior freqüência de cães positivos ocorreu em dois postos de vacinação localizados na periferia da cidade (14,1 e 8,2\%), cujos proprietários eram de baixa renda. Nessas áreas periféricas verificou-se elevado número de animais criados soltos nas ruas e alta freqüência de machos positivos (66,7 e 71,4\% nos dois postos), significativamente maior do que a de fêmeas. Nos outros postos não se observou diferença entre sexos quanto à porcentagem de animais positivos.

Pode-se concluir que a prevalência da brucelose canina na cidade de Alfenas é alta e constitui um problema para o serviço de saúde pública, principalmente quanto aos cães criados nas ruas.

Palavras-chave: cão, Brucella canis, Brucella abortus, brucelose canina, diagnóstico

\begin{abstract}
The prevalence of canine brucellosis was evaluated in the city of Alfenas, MG through the technique of agarose gel imunodifusion for Brucella canis and slow serum agglutination test with 2-mercaptoetanol for Brucella abortus. The prevalence was of $14.2 \%$ and $2.8 \%$, respectively, for B. canis and B. abortus. The positives, characterized by animals above one year of age (77.8\%), and mongrel dogs (56.2\%), showed a prevalence of 50 and $48 \%$ for males and females, respectively. The canine brucellosis was prevalent in the city principally in dogs of outskirts.
\end{abstract}

Keywords: dog, Brucella canis, Brucella abortus, canine brucellosis, diagnosis

\section{REFERÊNCIAS BIBLIOGRÁFICAS}

ALMEIDA, A.C.; MENESES, A.M.; BERNIS,V.M.O. et al. Soroprevalência da brucelose canina na cidade de Alfenas, MG. Dados preliminares. Arq. Bras. Med. Vet. Zootec., v.53, p.358-360, 2001.

ALTON, G.G.; JONES, L.M.; ANGUS, R.D. et al. Techniques for the brucellosis laboratory. Paris: Inra, 1988. 190p.

AUGUSTO, P.H.; ALMEIDA, A.C.; FRANCESCHINI, F.S. et al. Soroprevalência da Brucelose Animal na Região Sul de Minas Gerais In: ENCONTRO de iniciação científica latino americano, 6. 2002, São José dos Campos. Anais... São José dos Campos, 2002. p.45-50.

CHARMICHAEL, L.E.; SHING, S.J. Canine brucellosis: a diagnostician`s dilemma. Semin. Vet. Med. Surg. (Small Anim.), v.11, p.161-165, 1996.

MAIA, G.R.; ROSSI, C.R.S.; ABRADIA, F. et al. Prevalência da brucelose canina nas cidades do Rio de
Janeiro e Niteroi- RJ. Rev. Bras. Reprod. Anim., v.23, p.425-427, 1999.

MARASSI, C.D.; MORAES, I.A.; LILENBAUM, W. Soroprevalência de brucelose canina em cães domiciliados do município do Rio de Janeiro-RJ. Disponível em: $\quad$ http://www.uf.br/fisiovet/ docentesfisiovet/brucelose-conbravet.htm. $>$ Acesso em 21 de Julho de 2003.

MEGID, J.; BRITO, A.F.; MORAES, C.C.G. et al. Epidemiological assessment of canine brucellosis . Arq. Bras. Med. Vet. Zootec., v.51, p.439-440, 1999.

MOLNAR, L.; MOLNAR, E.; CARVALHO, M. Capacidade de algumas provas sorológicas no diagnóstico de brucelose canina. Hora Vet., p.45-49, 2001.

MORAES, C.C.G.; MEDGI, J.; SOUZA, L.C. et al. Prevalência da brucelose canina na microrregião da Serra de Botucatu, São Paulo, Brasil. Arq. Inst. Biol., v.69, p.710, 2002. 